\title{
Single droplet combustion of aluminum nanoparticles added to a biofuel: effect of particle concentration and ambient temperature
}

\author{
Inês A. S. Ferrão*1,2,3, Miguel A. A. Mendes ${ }^{2}$, Ana. S. O. H. Moita ${ }^{3,4}$, André R. R. Silva ${ }^{1}$ \\ ${ }^{1}$ AEROG-LAETA, Universidade da Beira Interior, Covilhã, Portugal \\ ${ }^{2}$ IDMEC-LAETA, Instituto Superior Técnico, Universidade de Lisboa, Lisboa, Portugal \\ ${ }^{3} \mathrm{IN}^{+}$-LARSyS, Instituto Superior Técnico, Universidade de Lisboa, Lisboa, Portugal \\ ${ }^{4}$ CINAMIL, Portuguese Military Academy, Lisboa, Portugal \\ ${ }^{*}$ Corresponding author email: ines.ferrao@ubi.pt
}

\begin{abstract}
The fast expansion and growth of the aviation sector, coupled with the greenhouse gas and pollutant emissions, requires urgent solutions. A starting point to change this sector paradigm could be a new energy source for aviation gas turbines, focused on potential carbon neutral fuels, e.g., biofuels. A possible solution is nanoparticles addition to improve the biofuel properties and mitigate the problems inherent to their use. The present work experimentally evaluates the combustion characteristics of single droplets of HVO (NExBTL) with aluminum nanoparticles. The ambient temperature was varied from $600{ }^{\circ} \mathrm{C}$ to $1000{ }^{\circ} \mathrm{C}$. Three particle concentrations $(0.2$, 0.5 , and $1.0 \mathrm{wt} . \%$ ) were investigated with a fixed particle size of $40 \mathrm{~nm}$. This study examined the combustion of droplets with an initial diameter of $250 \mu \mathrm{m}$ using a falling droplet method. The results reveal that for nanofuels, the droplet size evolution curve is not in agreement with $D^{2}$ - law and display a unique disruptive burning phenomenon at the end of the droplet lifetime. It was noticed that the burning rate of biofuel is considerably enhanced with the addition of nanoparticles, being the highest value for the nanofuel with a particle concentration of $1.0 \mathrm{wt} . \%$.
\end{abstract}

\section{Keywords}

Alternative fuels, nanofuel, single droplet combustion, drop tube furnace.

\section{Introduction}

The combustion of liquid fuels is a complex phenomenon employed in several applications such as gas turbines, diesel, and spark-ignition. The liquid fuel is atomized and dispersed at the combustion chamber, leading to the vaporization of cloud of droplets. The fuel is then mixed with the oxidant and finally ignition occurs.

To better comprehend spray combustion, a pre-requisite is understanding single droplet evaporation and combustion [1]. In the last decades, numerous studies were developed regarding single droplet evaporation and combustion involving mono and multi-component fuels. Pacheco et al. [2] evaluated single droplet combustion of jet-fuel, HVO biofuel, and their blends in a drop tube furnace. The introduction of alternative fuels in aviation is a subject that requires particular attention due to environmental concerns. This sector is specially sourced by a single fuel derived from fossil fuels. This fact, allied with the greenhouse gas and pollutant emissions, induce an interest in including an alternative energy source [3]. Biofuels are a renewable source derived from sustainable feedstock that reduce the pollutant emissions. Few biofuel technologies are approved and incorporated in the aviation sector, namely SIP-SPK, FT-SPK, FT-SPK/A, and HEFA. Hydroprocessed Esters and Fatty Acids (HEFA) produce alternative fuel based on vegetable oils with similar properties to conventional fuel with advantages including lower aromatic content [4]. However, these fuels also present drawbacks, mainly in viscosity, volatility properties that affect atomization and consequently combustion efficiency. Recently, the addition of nanoparticles has been proposed as a possible solution to enhance biofuel combustion performance [5]. Nanoparticles suspended in a liquid fuel as a potential secondary energy carrier have been recently studied due to nanotechnology development. These particles offer a 
higher specific surface area and higher reactivity, and enhance thermophysical properties such as thermal conductivity, thermal diffusivity, viscosity, and convective heat transfer coefficients when compared with the base fuel [6]. Tyagi et al. [7] studied the ignition probability of diesel with aluminum and aluminum oxide nanoparticles. The authors reported that the ignition probability increases with the addition of nanoparticles compared to pure diesel. Tanvir and Qiao [8] evaluated the effect of particle concentration and droplet size of pure ethanol and ethanol with aluminum nanoparticles in a droplet stream combustion experiment. The study reveals that the droplet burning rate increases with increasing particle concentration, and the burning rate enhancement is mainly attributed to the radiation absorption of the nanoparticles suspended within the droplets. Focusing on a suspended droplet experiment, Javed et al. [9] performed an investigation to understand the effects of high ambient temperatures and various concentrations of nanoparticles on the autoignition and combustion characteristics of heptane-based droplets. The authors reported that at higher temperatures $\left(750-850{ }^{\circ} \mathrm{C}\right)$, the burning rate of heptane $+\mathrm{n}$-Al droplets was considerably increased compared to pure heptane droplets, regardless of particle concentration. This observation was attributed to the occurrence of droplet ruptures that promote a substantially reduced burning time and total combustion time. Increasing the particle concentration, micro-explosions are observed to occur more intensively. Similar phenomena were also reported by $[10,11]$. Micro-explosions are identified as a disruptive burning phenomena that appear in the droplet lifetime and influence the combustion process. To further study the combustion of nanofuel droplets in a falling droplet method, the present work discusses the effect of particle concentration and the ambient temperature of aluminum nanoparticles suspended in aviation biofuel. The purpose is to study micrometer droplets (pure and nanofuel) in an experimental arrangement with considerable high temperatures $\left(600{ }^{\circ} \mathrm{C}\right.$, $800{ }^{\circ} \mathrm{C}, 1000{ }^{\circ} \mathrm{C}$ ) without using suspended fiber to avoid heterogeneous boiling promoted by a nucleating surface. Droplet size evolution and disruptive burning phenomena at the different operating conditions will be described in detail.

\section{Material and methods \\ Nanofuel preparation}

In the present work, three nanofuels with different concentrations were studied. Additionally, pure HVO was also tested for comparison purposes. The base fuel adopted was NExBTL (Neste Renewable Diesel), an HVO biofuel from Neste. Table 1 shows the properties of HVO and jet-fuel $[2,12]$.

Table 1. HVO and jet-fuel properties [2, 12]

\begin{tabular}{c|cc}
\hline Parameter & HVO & Jet A-1 \\
\hline Density $\left(\mathrm{kg} / \mathrm{m}^{3}\right)\left(\right.$ at $\left.20{ }^{\circ} \mathrm{C}\right)$ & 780.6 & 798 \\
Surface tension $(\mathrm{N} / \mathrm{m})\left(\right.$ at $\left.20{ }^{\circ} \mathrm{C}\right)$ & 0.0265 & 0.0247 \\
Kinematic viscosity $\left(\mathrm{mm}^{2} / \mathrm{s}\right)\left(\right.$ at $\left.25^{\circ} \mathrm{C}\right)$ & 4.33 & 1.40 \\
Sulfur $(\mathrm{wt} . \%)$ & 0.09 & 0.3 \\
Aromatics $(\mathrm{wt} . \%)$ & 0 & 13.8 \\
Final boiling point $\left({ }^{\circ} \mathrm{C}\right)$ & 308 & 237 \\
Lower heating value $(\mathrm{MJ} / \mathrm{kg})$ & 43.9 & 43 \\
Distillation 10 vol. $\%\left({ }^{\circ} \mathrm{C}\right)$ & 262 & 170
\end{tabular}

To accomplish the main objective of this work, aluminum nanoparticles were added to the biofuel. Aluminum shows many advantages in diverse fields. This metal is an excellent conductor of heat, has a relatively low cost, high combustion energy, and easy to acquire. To study nanofuel droplets, a specific procedure was performed. The purpose was to achieve a stable nanofuel with a low level of aggregation. The particle size used in this work was $40 \mathrm{~nm}$. Three different concentrations were considered: $0.2,0.5$ and $1.0 \mathrm{wt} . \%$. The nanofuel preparation 
begins with a mixture of the base fuel with nanoparticles, using a magnetic stirrer for twenty minutes. The mixture is then maintained at the sonicator (model UP200Ht by Hielscher) in an ice bath for approximately 30 minutes. The stability was evaluated through the sedimentation visualization in different test tubes. No obvious sedimentation was noticed during the experiments. The nanofuel properties tested are presented in table 2. The density was measured with the pycnometer method and the viscosity with a rheometer (TA instruments ARI 500 ex) at ambient temperature with an accuracy of $\pm 5 \%$. The surface tension was determined with the pendant drop method using an optical tensiometer THETA (Attension) [13].

Table 2. Physical properties of nanofuels.

\begin{tabular}{c|ccc}
\hline Nanofuels & $\begin{array}{c}\text { Density } \\
\left(\mathrm{kg} / \mathrm{m}^{3}\right)\end{array}$ & $\begin{array}{c}\text { Surface tension } \\
(\mathrm{N} / \mathrm{m})\end{array}$ & $\begin{array}{c}\text { Viscosity } \\
(\text { Pa.s })\end{array}$ \\
\hline $\mathrm{HVO}+\mathrm{n}-\mathrm{Al} 40 \mathrm{~nm}(0.2 \mathrm{wt} \%)$ & 770.5 & 0.0266 & 0.020 \\
$\mathrm{HVO}+\mathrm{n}-\mathrm{Al} 40 \mathrm{~nm}(0.5 \mathrm{wt} \%)$ & 771.6 & 0.0265 & 0.020 \\
$\mathrm{HVO}+\mathrm{n}-\mathrm{Al} 40 \mathrm{~nm}(1.0 \mathrm{wt} \%)$ & 773.2 & 0.0267 & 0.055
\end{tabular}

\section{Experimental setup}

The single droplet evaporation/combustion process occurs in a drop tube furnace, as shown in Figure 1. To support this, an illumination set, an acquisition system, and an injector device are also present in the experimental setup. The drop tube furnace (DTF) is composed of electrically heated coils and can achieve wall temperatures up to $1200{ }^{\circ} \mathrm{C}$. A quartz tube with an inner diameter of $6.6 \mathrm{~cm}$ and a length of $82.6 \mathrm{~cm}$ is placed at the DTF interior, where the air and droplet injection occurs. The DTF has two windows dedicated to optical access. The illumination set is placed in a window opposite to the acquisition system.

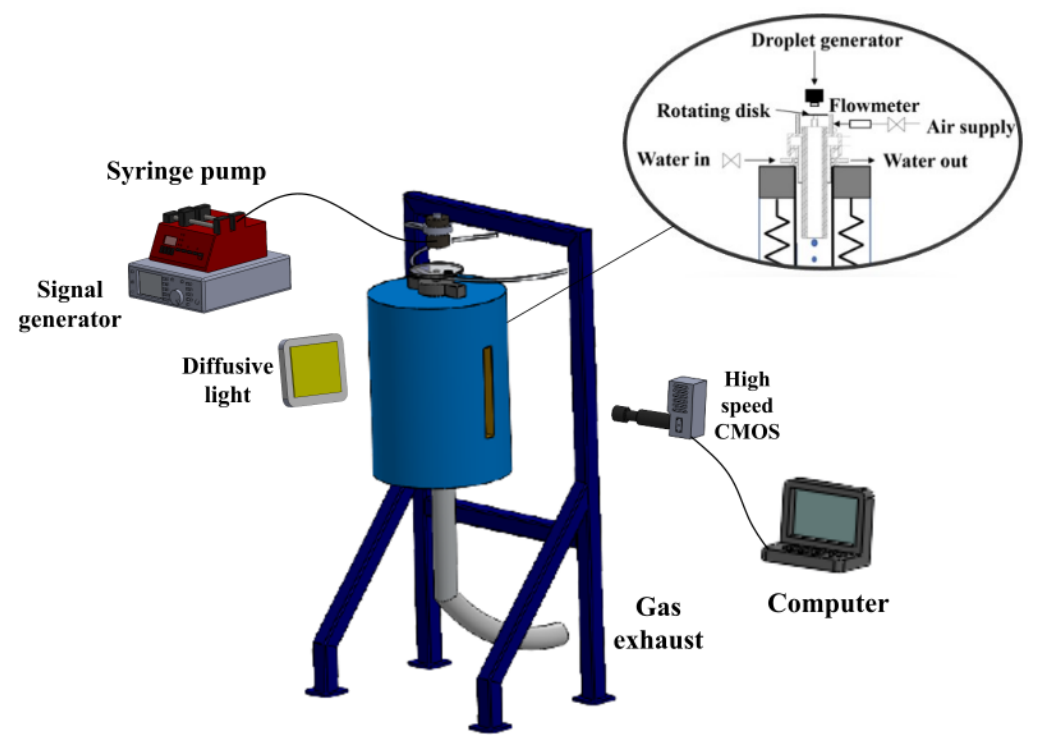

Figure 1. Schematic of the experimental setup.

The illumination set comprises a diffusive light to enhance the contrast and droplet visualization. Regarding the acquisition system, a high-speed CMOS camera and a computer was used. A high magnification lens (Zoom $6000 \AA$ Lens System) is coupled to the camera CR600x2 from Optronics. The magnification lens is composed of a $6.5 \times Z$ oom, $12 \mathrm{~mm} F F$, a $0.25 \times$ lens attachment and a 2.0xshort adapter, with a magnifying range of 0.35-2.25. The image acquisition was pursued with $1000 \mathrm{fps}$ with a resolution of $1200 \times 500$ pixels and an exposure time 
of $1 / 12000 \mathrm{~s}$. The droplet injection was generated with a TSI device, placed at the top of the drop tube furnace. It is a piezoelectric device with a pinhole of $200 \mu \mathrm{m}$ that produces a stream of droplets. This equipment is connected to a syringe pump and signal generator. Droplets were released with an initial diameter of $250 \mu \mathrm{m} \pm 8 \mu \mathrm{m}$, an acceptable compromise between practical applications and the experimental conditions. However, this device produces a stream of droplets, and due to this, there is no adequate spacing to guarantee a single droplet phenomenon. To increase the inter-droplet space, a rotating disk was placed on the DTF injector and droplet generator. The rotating disk has a diameter of $12 \mathrm{~cm}$ and a rotational speed of $1200 \mathrm{rpm}$ and possesses a slot with the dimensions of $1 \mathrm{~cm} \times 1 \mathrm{~cm}$. The image data processing was performed in the ImageJ software to evaluate the droplet size evolution, burning rate, among others. The droplet outline marked through the brightness gradient, allowing the droplet characteristics. For the optical configuration used in this work, the pixel size was $12 \mu \mathrm{m}$.

\section{Results and discussion}

\section{Visualization and description of pure HVO droplet}

As previously mentioned, pure HVO was tested for comparison purposes. Figure 2 shows the droplet size evolution of pure $\mathrm{HVO}$ at $\mathrm{T}=800{ }^{\circ} \mathrm{C}$. A visualization of the falling droplet of pure $\mathrm{HVO}$ and the correspondent droplet size evolution is presented. In this way, Figure 2 shows the square of the normalized droplet diameter as a function of the normalized time, where $D_{0}$ is the initial droplet diameter.
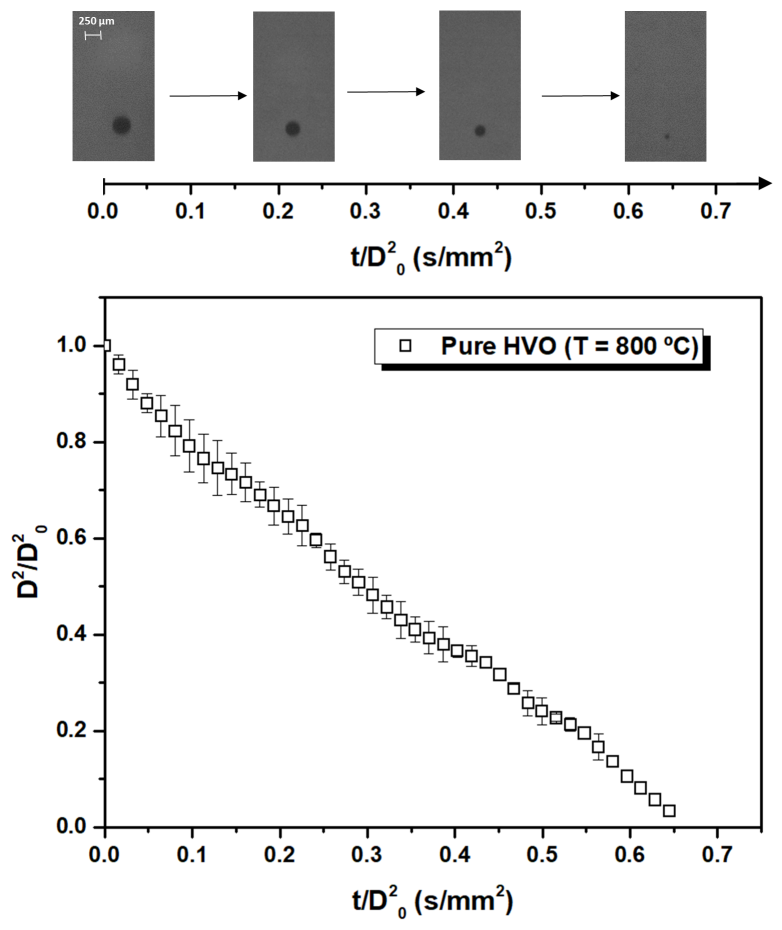

Figure 2. Droplet size evolution of pure $\mathrm{HVO}$ at $\mathrm{T}=800^{\circ} \mathrm{C}$.

For smoothen purposes, a three-point moving average was employed. Additionally, a statistical study was performed to ensure that the behavior of $D^{2}$ - law curves and burning rate were independent of sample size. Thus, in the present work, the droplet size evolution and burning rate were evaluated using 40 droplets.

When the droplet enters the quartz tube, a low intensity flame at the droplet wake is formed. The droplet with an initial diameter of $250 \mu \mathrm{m}$ evaporates and burns as a fully liquid droplet without the occurrence of any disruptive burning phenomena. As time evolves, the diameter re- 
duces, being the end of the droplet lifetime pronounced at approximately $t / D_{0}^{2}=0.65\left(\mathrm{~s} / \mathrm{mm}^{2}\right)$. The temporal evolution of the droplet size is an agreement with the $D^{2}-$ law. The classical liquid droplet combustion theory states that the normalized square diameter decreases linearly with time, with a nearly constant slope defined as the burning rate $(\mathrm{K})$. The burning rate values of pure HVO at different temperatures will be discussed in the following paragraphs.

In general, at $\mathrm{T}=600{ }^{\circ} \mathrm{C}$, the majority of the droplets does not auto-ignite, and to provide an accurate comparison in all operating conditions, the droplet size evolution and the burning rate at this specific temperature will not be analyzed and explained in detail. The data obtained for $\mathrm{T}=$ $1000{ }^{\circ} \mathrm{C}$ depicts the same observation as $\mathrm{T}=800^{\circ} \mathrm{C}$, meaning that the droplet size evolution follows the $D^{2}$-law, and due to the increase in the ambient temperature a reduction in the droplet lifetime is noticed. These observations are in concurrence with a previous experimental study, where no disruptive burning phenomena were detected for pure HVO at this exact temperature [2].

\section{Droplet size evolution and micro-explosions: Nanofuels with different particle concen- tration and at different ambient temperature}

Figure 3 shows the droplet size evolution for all the fuels used in this work at different temperatures. Each curve was performed using 40 droplets and a three-point moving average.

Figure 3 (a) shows the $D^{2}$ curves for pure HVO and three nanofuels with different concentrations at $\mathrm{T}=800{ }^{\circ} \mathrm{C}$. As mentioned, the normalized droplet diameter evolution of pure HVO obeyed the $D^{2}$ - law. However, with the addition of nanoparticles to the biofuel, a distinct conclusion was achieved. For HVO $+40 \mathrm{~nm}$ with 0.5 and $1.0 \mathrm{wt} \%$, a particular tendency is noticed. The presence of nanoparticles in a given concentration could hinder the evaporation rate at the end of the droplet lifetime, altering the droplet size evolution curve and consequently not following the $D^{2}-$ law.

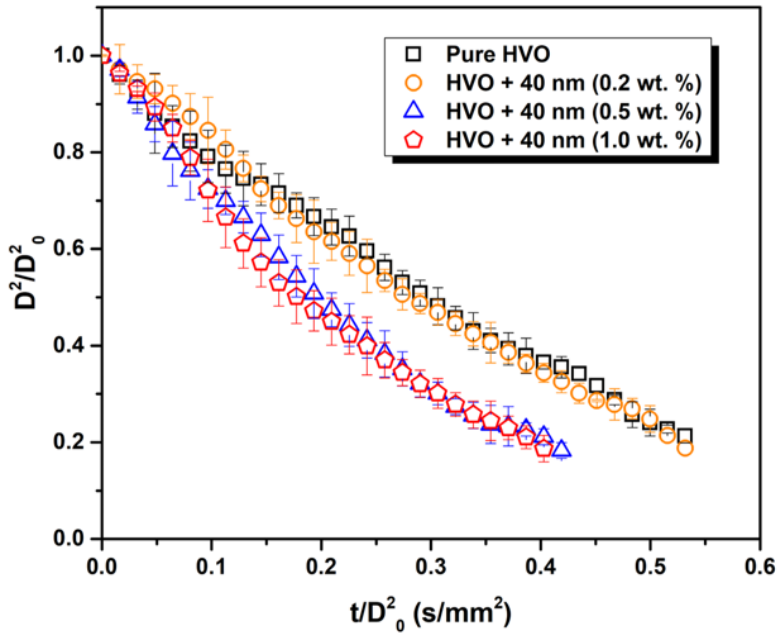

(a)

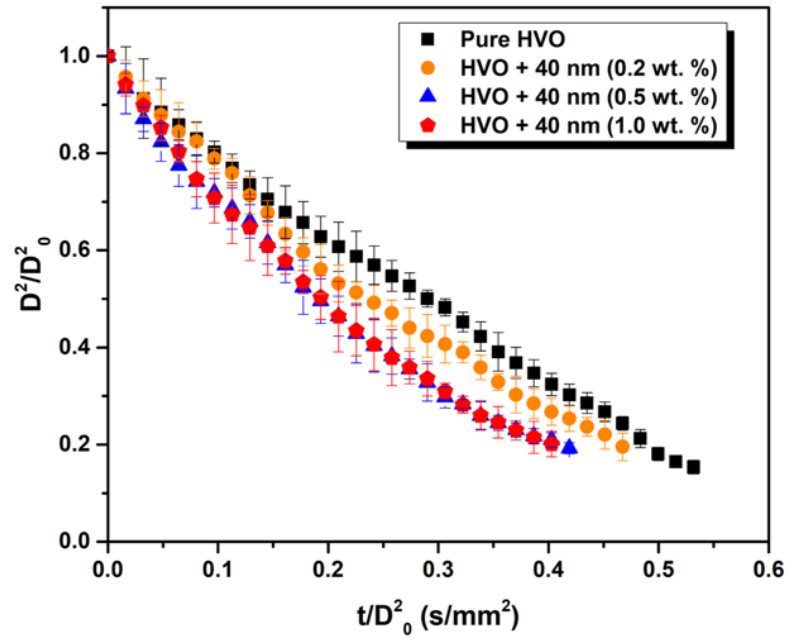

(b)

Figure 3. (a) Droplet size evolution of pure HVO and nanofuels at $\mathrm{T}=800{ }^{\circ} \mathrm{C}$; (b) Droplet size evolution of pure HVO and nanofuels at $\mathrm{T}=1000{ }^{\circ} \mathrm{C}$.

At particle concentrations of 0.5 and $1.0 \mathrm{wt} . \%$, a significant reduction in the temporal evolution of the droplet diameter is detected in comparison with the pure HVO. Nevertheless, at a lower particle concentration $(0.2 \mathrm{wt} . \%)$, the results reveal that the droplet size evolution curve practically overlaps with the $D^{2}$ curve of pure HVO. This means that decreasing the particle concentration at a lower ambient temperature did not influence in a considerable way the droplet diameter of a nanofuel when compared with a pure fuel. This fact can be related to a decrease ambient temperature and also a lower radiation emission inside the drop tube furnace at lower 
temperatures. However, when the ambient temperature is increased to $\mathrm{T}=1000{ }^{\circ} \mathrm{C}$, the tendency was not maintained. Figure 3 (b) shows the temporal evolution of pure HVO and three nanofuels at a higher temperature $\left(T=1000{ }^{\circ} \mathrm{C}\right)$. It was observed that the particle concentration of 0.5 and $1.0 \mathrm{wt} . \%$ presents a faster droplet diameter reduction when compared to pure HVO. Additionally, for these nanofuels, the curves are not in agreement with $D^{2}-$ law. A remarkable fact is detected for HVO + $40 \mathrm{~nm}(0.2 \mathrm{wt} . \%)$. At a higher temperature, an enhancement in the evaporation rate occurs, is noticeable the offset of the pure biofuel and nanofuel droplet size evolution curves. Clearly, the addition of aluminum nanoparticles in biofuel influences the temporal evolution droplet diameter and its lifetime. For all the nanofuels, regardless of the ambient temperature, micro-explosions are detected pronouncing the end of the droplet lifetime. According to Ismael et al. [14], micro-explosions occur when the primary droplet disintegrates as a rapid breakup of fuel droplets leading to smaller droplets, enhancing fuel evaporation hence improving the air-fuel mixing process.

Figure 4 shows a sequence of images of micro-explosions for the nanofuels with different particle concentrations. As the liquid is evaporating, the nanoparticles remain inside the droplet.

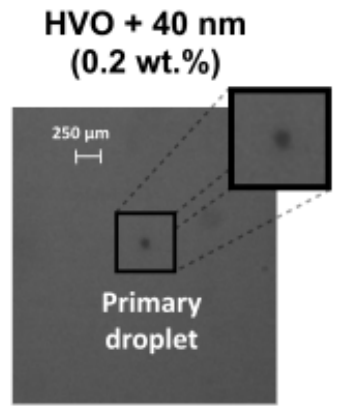

$\mathrm{t}=40 \mathrm{~ms}$

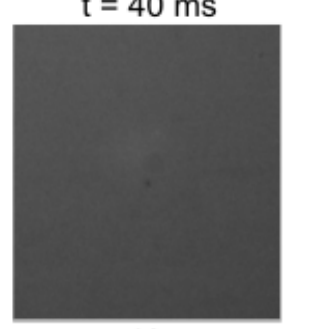

$\mathrm{t}=46 \mathrm{~ms}$

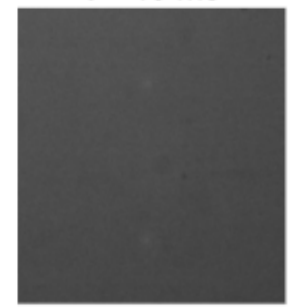

$\mathrm{t}=47 \mathrm{~ms}$

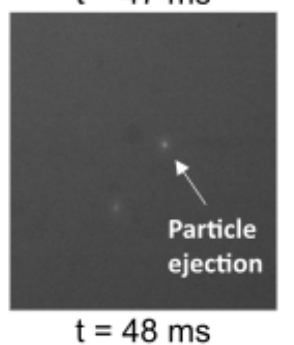

(a)

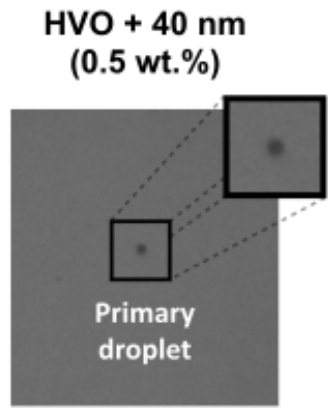

$\mathrm{t}=34 \mathrm{~ms}$

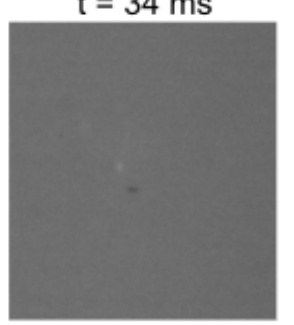

$\mathrm{t}=40 \mathrm{~ms}$

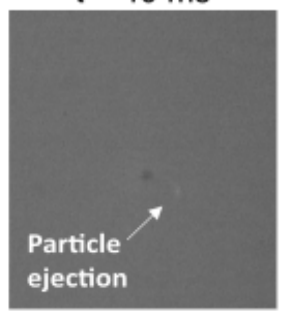

$\mathrm{t}=41 \mathrm{~ms}$

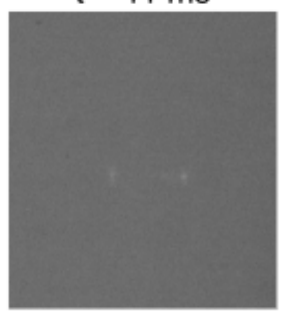

$\mathrm{t}=42 \mathrm{~ms}$

(b)

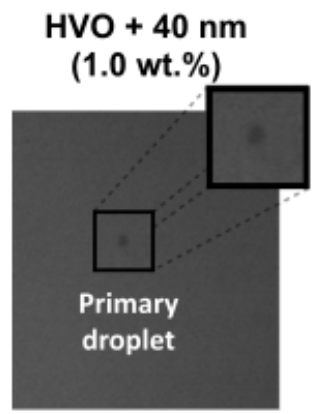

$\mathrm{t}=26 \mathrm{~ms}$

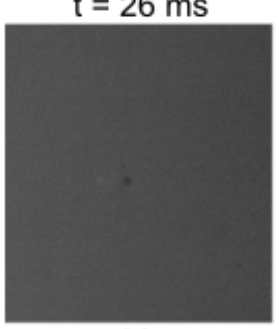

$\mathrm{t}=30 \mathrm{~ms}$

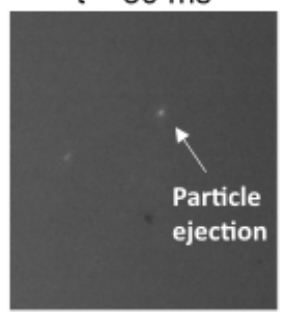

$\mathrm{t}=31 \mathrm{~ms}$

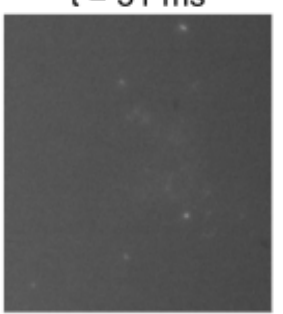

$\mathrm{t}=32 \mathrm{~ms}$

(c)

Figure 4. Sequence of images of micro-explosions at $\mathrm{T}=1000{ }^{\circ} \mathrm{C}$ : (a) $\mathrm{HVO}+40 \mathrm{~nm}(0.2 \mathrm{wt} \%$ ), (b) $\mathrm{HVO}+40 \mathrm{~nm}$ (0.5 wt.\%), (c) HVO + $40 \mathrm{~nm}$ (1.0 wt.\%). 
At this stage, the solid phase is predominant. Due to this, the appearance of local hot spots promote the occurrence of micro-explosions. This disruptive burning phenomenon is detected when the primary droplet disintegrates and occurs the ejection of particle agglomerates in several directions. These agglomerate ignite, promoting intense bright spots. The onset and intensity of micro-explosions depend greatly on particle concentration. For the highest particle concentration, micro-explosions occur earlier, as shown in Figure 4 (c). Thus, for HVO $+40 \mathrm{~nm}$ (0.2 wt.\%), HVO + $40 \mathrm{~nm}$ (0.5 wt.\%) and HVO + $40 \mathrm{~nm}$ (1.0 wt.\%), micro-explosions appear at $\mathrm{t}=46 \mathrm{~ms}, \mathrm{t}=40 \mathrm{~ms}$ and $\mathrm{t}=30 \mathrm{~ms}$, respectively. Moreover, HVO $+40 \mathrm{~nm}$ (1.0 wt.\%) promotes a micro-explosion with a large number of bright spots in a wider region. As reported in the literature, the micro-explosions identified in the nanofuel droplet combustion are a mechanism responsible for reducing the droplet lifetime [15]. Similar findings were observed in the present work, being the pure HVO the fuel with the longest lifetime.

\section{Burning rate: Comparison between pure HVO and HVO with aluminum nanoparticles}

Table 3 shows the burning rate for all the fuels tested in this study. Similarly to the droplet size evolution, to examine the droplet burning rate, 40 droplets were considered. In terms of comparison, the values were analyzed until $D^{2} / D_{0}^{2}=0.2$ as displayed in the earlier figures. The average burning rate was determined by $\mathrm{K}=-\mathrm{d}\left(\mathrm{D}^{2}\right) / \mathrm{dt}$.

Pure HVO presents the lowest burning rate for all the ambient temperature tested. A slight increase in its burning rate was noticed from $\mathrm{T}=800{ }^{\circ} \mathrm{C}$ to $\mathrm{T}=1000{ }^{\circ} \mathrm{C}$, leading to burning rate values from 1.46 to $1.65 \mathrm{~mm}^{2} / \mathrm{s}$, respectively. Interestingly, as noticed in the droplet size evolution, nanofuels present higher burning rates regardless of particle concentration and ambient temperature. Focusing on the ambient temperature, the results show that the higher burning rate occurs at the higher ambient temperature $\left(T=1000{ }^{\circ} \mathrm{C}\right)$ for all the fuels.

In this way, HVO + $40 \mathrm{~nm}(1.0 \mathrm{wt} . \%)$ presents the highest value. On the other hand, particle concentration also has a notorious influence on the burning rate. Regardless of the ambient temperature, decreasing the particle concentration leads to a decrease in the burning rate, being the lowest value for HVO + $40 \mathrm{~nm}$ (0.2 wt.\%).

These remarks are related to the presence of nanoparticles stably suspended in a biofuel that enhances the evaporation/burning process. Moreover, for the present experimental conditions, an improvement in the biofuel combustion performance was noticed, and throughout this work, it was proved that the radiative absorption and the occurrence of micro-explosions are also highly relevant in this field of study [15].

Table 3. Burning rate $(\mathrm{K})\left[\mathrm{mm}^{2} / \mathrm{s}\right]$.

\begin{tabular}{c|cc}
\hline Fuels & $\mathbf{T = 8 0 0}{ }^{\circ} \mathbf{C}$ & $\mathbf{T}=\mathbf{1 0 0 0}{ }^{\circ} \mathbf{C}$ \\
\hline Pure HVO & $1.46 \pm 0.16$ & $1.65 \pm 0.15$ \\
HVO + 40 $\mathrm{nm}$ (0.2 wt.\%) & $1.58 \pm 0.17$ & $1.76 \pm 0.18$ \\
HVO + 40 nm (0.5 wt.\%) & $1.96 \pm 0.26$ & $1.99 \pm 0.33$ \\
HVO + 40 nm (1.0 wt.\%) & $2.05 \pm 0.22$ & $2.10 \pm 0.23$
\end{tabular}

\section{Conclusions}

The objective of the present work is to evaluate the addition of aluminum nanoparticles in a biofuel. Moreover, the effect of particle concentration and ambient temperature were investigated. It was concluded that only the pure biofuel obeyed the $D^{2}$-law. The droplet size evolution of nanofuels does not follow the $D^{2}$-law, and is considerably influenced by the particle concentration and ambient temperature. At the end of the nanofuel lifetime, disruptive burning phenomena appear. The micro-explosion onset and intensity depend on the particle concentration. Thus, increasing the particle concentration leads to an earlier occurrence of the micro-explosions and a higher intensity. Additionally, it was noticed an increase in the biofuel 
burning rate when aluminum nanoparticles were added. Regardless of the ambient temperature, the pure HVO presents the lowest burning rate. On the other hand, the nanofuel with the highest concentration shows a higher burning rate.

\title{
Acknowledgements
}

Inês Ferrão acknowledges Fundação para a Ciência e Tecnologia (FCT) for the provision of Ph.D scholarship with the reference SFRH/BD/144688/2019. The present work was performed under the scope of the Laboratório Associado em Energia, Transportes e Aeronáutica (LAETA) and Laboratório de Robótica e Sistemas de Engenharia (LARSyS) activities and it was supported by FCT through the projects number UIDB/50022/2020 and UIDB/50009/2020. Authors would also like to acknowledge Fundação para a Ciência e Tecnologia for partially supporting this work through project PTDC/EME-SIS/2017.

\author{
Nomenclature \\ $D \quad$ Droplet diameter [m] \\ $D_{0} \quad$ Initial droplet diameter [m] \\ $K \quad$ Burning rate $\left[\mathrm{m}^{2} / \mathrm{s}\right]$ \\ $t \quad$ Time [s] \\ T Temperature $\left[{ }^{\circ} \mathrm{C}\right]$
}

\section{References}

[1] Aggarwal, S. K., 2014, Progress in Energy and Combustion Science, 45, pp. 79-107.

[2] Pacheco, G., Silva, A., Costa, M., 2021, Energy \& Fuels.

[3] Blakey, S., Rye, L., Wilson, C. W., 2011, Proceedings of the combustion institute, 33(2), pp. 2863-2885.

[4] Tao, L., Milbrandt, A., Zhang, Y., Wang, W. C., 2017), Biotechnology for biofuels, 10 (1), pp. 1-16.

[5] Lee, C. C., Tran, M. V., Tan, B. T., Scribano, G., Chong, C. T., 2020, Fuel, 119749.

[6] Yu, W., Xie, H., 2012, Journal of nanomaterials.

[7] Tyagi, H., Phelan, P. E., Prasher, R., Peck, R., Lee, T., Pacheco, J. R., Arentzen, P., 2008, Nano letters, 8 (5), pp. 1410-1416.

[8] Tanvir, S. and Qiao, L., 2015, Journal of Propulsion and Power, 31(1), pp. 408-415.

[9] Javed, I., Baek, S. W., Waheed, K., 2015, Combustion and Flame, 162 (1), pp. 191-206.

[10] Wang, J., Qiao, X., Ju, D., Wang, L., Sun, C., 2019, Energy, 183, pp. 149-159.

[11] Javed, I., Baek, S. W., Waheed, K., 2014, Experimental thermal and fluid science, 56, pp. 33-44.

[12] Pizziol, B., Costa, M., Panão, M. O., Silva, A., 2018, Experimental Thermal and Fluid Science, 96, pp. 303-310.

[13] Moita, A. S., Laurência, C., Ramos, J. A., Prazeres, D. M. F., Moreira, A. L. N., 2016, Journal of Bionic Engineering, 13 (2), pp. 220-234.

[14] Ismael, M. A., Heikal, M. R., Rashid, A., Aziz, A., Crua, C., 2016, ARPN Journal of Engineering and Applied Sciences, 11 (20), pp. 11975-11981.

[15] Emekwuru, N. G., 2019, Journal of the Indian Institute of Science, 99 (1), pp. 43-58. 